\title{
Endoscopic retrieval of a disrupted pancreatic stent using a nasopancreatic drainage tube
}

A proximally migrated pancreatic stent is usually removed using a basket, balloon, snare or forceps [1-3]. The lasso technique [4] and its variation [5] have been described. However, no method for retrieval of a migrated pancreatic stent has been established. We retrieved a disrupted pancreatic stent using a nasopancreatic drainage tube (NPDT).

A 45-year-old man underwent pancreatic stent placement for chronic pancreatitis. The stent became disrupted 4 months after placement ( $\bullet$ Fig. 1 ).

The distal part of the stent was removed; however, the proximal part could not be retrieved and remained in the body of the main pancreatic duct (MPD), despite attempts at removal using biopsy forceps, basket, balloon and a Soehendra stent retriever. These attempts led to the migration of the pancreatic stent upstream. So, a guide wire was inserted through the lumen of the stent ( Fig. 2), and then a 5-Fr NPDT was inserted over the wire until it extended beyond the stent.

As the NPDT was gently pulled out, the stent moved with it toward the duodenum ( $\bullet$ Fig. 3).

The first flap of the NPDT was stuck into a side hole of the pancreatic stent, and the second flap was resting just before the distal end of the stent ( $\bullet$ Fig. 4).

After removal, the flaps were seen to be nearly at right angles ( $\bullet$ Fig. 5).

Removal of a migrated pancreatic stent using a basket or forceps is sometimes difficult. If the angle of the device in relation to the stent is not appropriate, the device will slip, cannot grasp the stent or will push it upstream. Inserting a 5-Fr NPDT is easy because it is slender and can be inserted over a guide wire. Grasping the stent is unnecessary. When a NPDT flap sticks into a side hole of the stent, removal will be possible in cases without stricture or a stone downstream of the main pancreatic duct.

Using a NPDT is one effective option for retrieval of a proximally migrated or disrupted pancreatic stent in the main pancreatic duct.

\section{Competing interests: None}

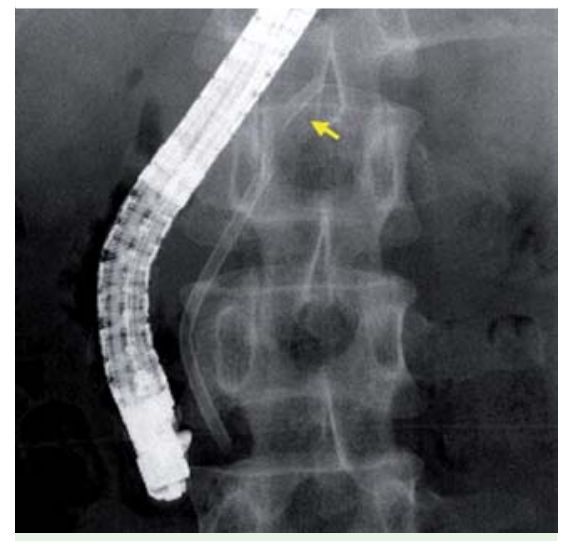

Fig. 1 The pancreatic stent was disrupted, with the proximal part remaining in the body of the main pancreatic duct (arrow).

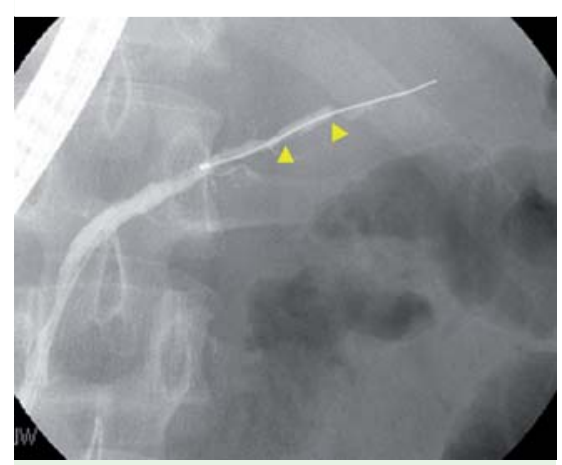

Fig. 2 A guide wire was inserted through the lumen of the pancreatic stent (arrowhead), which had moved upstream.

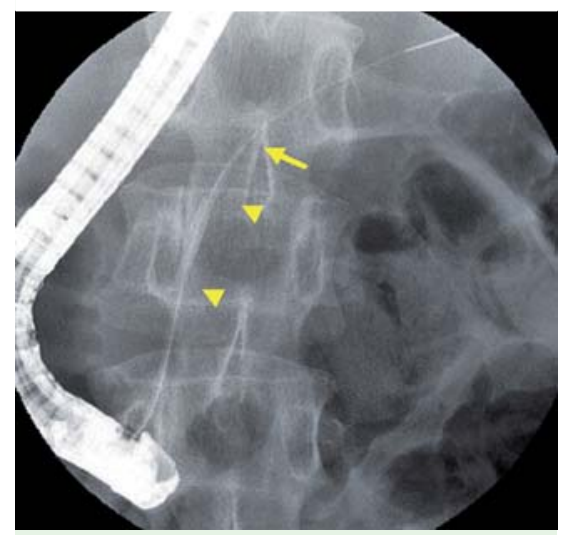

Fig. 3 When the nasopancreatic drainage tube (NPDT) was gently pulled out, the pancreatic stent (arrowhead) moved with the NPDT toward the duodenum (arrow: top of NPDT).

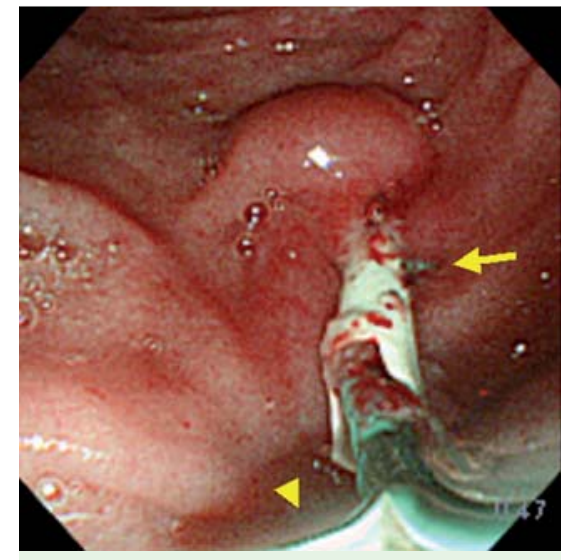

Fig. 4 One flap of the nasopancreatic drainage tube stuck into a side hole of the stent while a second flap rested just before the distal end of the disrupted pancreatic stent (arrow, first flap; arrowhead, second flap).

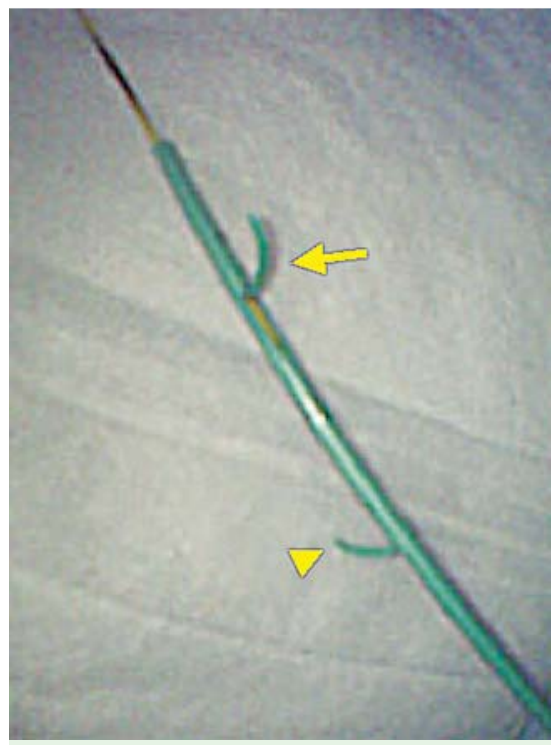

Fig. 5 Two flaps of the nasopancreatic drainage tube were open almost at right angles (arrow, first flap; arrowhead, second flap). 
Endoscopy_UCTN_Code_TTT_1AR_2AZ

T. Nambu, T. Ukita, H. Shigoka,

S. Omuta, I. Maetani

Division of Gastroenterology,

Department of Internal Medicine, Toho University Ohashi Medical Center, Tokyo, Japan

\section{References}

1 Price JH, Brandabur JJ, Kozarek RA et al. Good stents gone bad: endoscopic treatment of proximally migrated pancreatic duct stent. Gastrointest Endosc 2009; 70: 174-179

2 Sakai Y, Tsuyuguchi T, Ishihara T et al. Cholangiopancreatography troubleshooting: the usefulness of endoscopic retrieval of migrated biliary and pancreatic stents. Hepatobiliary Pancreat Dis Int 2009; 8: 632 - 637

3 Lahoti S, Catalano MF, Green JE et al. Endoscopic retrieval of proximally migrated biliary and pancreatic stents: experience of a large referral center. Gastrointest Endosc 1998; 47: 486-491

4 Sherman S, Hawes RH, Uzer MF et al. Endoscopic stent exchange using a guide wire and mini-snare. Gastrointest Endosc 1993; 39: 749-799

5 Villa JJ, Ruiz-Clavijo D, Fernandez-Urien et al. Endoscopic retrieval of a proximally migrated pancreatic stent: variation of the lasso technique. Endoscopy 2010; 42: E5 - E6
Bibliography

DOI $10.1055 / \mathrm{s}-0030-1255806$

Endoscopy 2010; 42: E308 -E309

(c) Georg Thieme Verlag KG Stuttgart · New York . ISSN 0013-726X

\section{Corresponding author}

\section{T. Nambu, MD}

Division of Gastroenterology

Department of Internal Medicine

Toho University Ohashi Medical Center

2-17-6 Ohashi

Meguroku Tokyo

Tokyo 153-8515

Japan

Fax: +81-3-34681269

tada@oha.toho-u.ac.jp 